\title{
Clustering History Data Penjualan Menggunakan Algoritma K-Means
}

\author{
Yogiswara Dharma Putra ${ }^{1}$, Made Sudarma ${ }^{2}$, Ida Bagus Alit Swamardika ${ }^{3}$ \\ [Submission: 26-03-2021, Accepted: 07-05-2021]
}

\begin{abstract}
The company has a desire to develop an increase in its business so that it is not eroded by the very tight business competition. Company $X$ is a company engaged in information technology and telecommunications. The amount of data on goods from the inventory carried out is still global, so grouping is needed. History of sales data becomes data that can be used in viewing the flow of goods movement from the most desirable to the least desirable. This is needed as the next reference for companies in making inventory to support sales and maintain customer satisfaction. This study uses a clustering method which is a method that can be used to see the level of sales that have been made based on the formed clusters. The K-Means algorithm is a suitable method to process sales history data because it has a fairly easy implementation, the time needed to run the process is relatively fast and easy to adapt than other clustering methods. The results of the application of the K-Means algorithm formed 3 clusters representing categories of high interest, interest, and least interest. In the most interested category there are 5 total items, in the interested category there are 4 total items, and 14 items less interested. These results are expected to help create quality goods to maintain product quality and customer satisfaction.
\end{abstract}

Keywords - Clustering, K-Means Algorithm, Sales

Intisari- Perusahaan memiliki keinginan dalam mengembangkan peningkatan usahanya agar tidak tergerus dalam persaingan bisnis yang sangat ketat. Perusahaan $X$ merupakan sebuah perusahaan yang bergerak dalam bidang teknologi informasi dan telekomunikasi. Jumah data barang dari persediaan yang dilakukan masih bersifat global sehingga perlu adanya pengelompokkan. History data penjualan menjadi data yang dapat digunakan dalam melihat arus pergerakan barang dari yang paling diminati hingga kurang diminati. Hal itu diperlukan sebagai acuan berikutnya bagi perusahaan dalam melakukan persediaan barang untuk menunjang penjualan dan menjaga kepuasan dari pelanggan. Penelitian ini menggunakan sebuah metode clustering yang merupakan sebuah metode yang bisa digunakan dalam melihat tingkat penjualan yang telah dilakukan berdasarkan cluster yang terbentuk. Algoritma $K$ Means menjadi metode yang cocok dapat mengolah history data penjualan dikarenakan memiliki pengimplementasian yang cukup mudah, waktu yang dibutuhkan dalam menjalankan prosesnya cukup relatif cepat dan mudah untuk diadaptasikan dari pada metode clustering lainnya.

${ }^{1}$ Mahasiswa, Magister Teknik Elektro Universitas Udayana, Gedung Pascasarjana Universitas Udayana Jl. PB Sudirman Denpasar-Bali, Kode Pos: 80232;( telp/fax: 0361-239599; e-mail: yogiswara.dharma@student.unud.ac.id)

2, 3 Dosen, Magister Teknik Elektro Universitas Udayana, Gedung Pascasarjana Universitas Udayana Jl. PB Sudirman Denpasar-Bali, Kode Pos: 80232; (tlp/fax: 0361-239599; e-mail: msudarma@unud.ac.id,gusalit@unud.ac.id)
Hasil dari penerapan algortima $\mathbf{K}$-Means terbentuk 3 cluster yang mewakili kategori sangat diminati, diminati dan kurang diminati. Pada kategori sangat diminati terdapat 5 jumlah item barang, kategori diminati terdapat 4 jumlah item barang dan kurang diminati terdapat 14 jumlah item barang. Hasil tersebut diharapkan dapat membantu dalam menciptakan barang yang berkualitas sehingga dapat menjaga kulitas produk serta kepuasan dari pelanggan.

Kata Kunci-Clustering, Algoritma K-Means, Penjualan

\section{PENDAHULUAN}

Setiap perusahaan dalam bidang perdagangan memiliki keinginan untuk mengembangkan usahanya dengan maksimal agar tidak tenggelam dalam persaingan bisnis yang berjalan sangat ketat. Banyak perusahaan yang melakukan berbagai cara agar tidak kalah dalam persaingan bisnis dengan menciptakan produk-produk terbaik untuk meningkatkan tingkat penjualan perusahaan. Perusahaan yang bergerak dalam bidang usaha dagang dan jasa bertujuan untuk dapat memperoleh laba dengan memanfaatkan sumber daya yang sudah dimiliki perusahaan.

Penelitian dilakukan pada sebuah perusahaan yang bergerak dalam bidang teknologi informasi dan komunikasi. Penelitian ini mengambil data objek pada perusahaan $\mathrm{X}$ dengan beberapa produk mulai dari laptop, komputer all in one, komputer desktop dan printer, kategori-kategori tersebut merupakan kebutuhan yang paling sering dibutuhkan oleh pelanggan perusahaan sehingga perlu adanya kemampuan untuk memperkirakan volume penjualan dari setiap produk yang dijual. Kepuasan pelanggan selalu menjadi prioritas agar dapat memenuhi kebutuhan pelanggan. Kebutuhan tersebut berdasarkan dari history penjualan yang sudah dilakukan sehingga dapat menjadi acuan dalam meningkatkan kualitas produk-produk berikutnya dalam melakukan perencanaan stok untuk menargetkan penjualan yang lebih baik sehingga mampu memberikan kepuasan bagi para pelanggan..

Data mining adalah sebuah proses yang dapat dilakukan untuk menemukan hubungan dari data yang belum diketahui oleh pengguna dengan menyajikannya dengan cara yang lebih mudah untuk dipahami agar dapat menjadi dasar dalam sebuah pengambilan keputusan [1][2].

Clustering adalah salah satu teknik dari data mining yang bertujuan untuk mengelompokkan data berdasarkan karakteristik kemiripan antara satu data dengan data lainnya [3]. Salah satu algoritma clustering yang dapat digunakan dalam mengelompokkan data berdasarkan karakteristik kemiripan adalah K-Means Clustering. Algoritma K-Means memiliki algoritma dengan mengelompokkan secara iteratif yang melakukan partisi data set ke dalam beberapa $\mathrm{K}$ cluster yang 
sudah ditentukan diawal yang dapat diimplementasikan dan dijalankan dengan relatif cepat dan mudah beradaptasi [4].

Penelitian mengenai algoritma K-Means sudah banyak dilakukan oleh para peneliti-peneliti dalam menunjang kebutuhan dari berbagai bidang. Algoritma K-Means digunakan dalam penelitian ini dikarenakan memiliki pengimplementasian yang cukup mudah, waktu yang dibutuhkan dalam menjalankan prosesnya cukup relatif cepat dan mudah untuk diadaptasikan, maka penelitian mengenai clustering data penjualan ini diharapkan bisa membantu perusahaan $\mathrm{X}$ dalam proses manajemen stok dan melihat peluang dari penjualan sebelumnya yang dapat menghasilkan produk terbaik sehingga dapat menjaga kualitas produk serta kepuasan dari pelanggan.

\section{KAJIAN PUSTAKA}

\section{A. Data Mining}

Data mining dikenal sejak tahun 1990, Ketika pekerjaan dalam pemanfaatan data menjadi sangat penting dalam berbagai bidang, mulai dari bidang bisnis, akademik dan lainnya [5]. Data mining digunakan karena mulai banyaknya jumlah data yang tersimpan dalam basis data. Data mining juga disebut sebagai knowledge discovery in database (KDD) ataupun pattern recognition. Istilah KDD disebut sebagai penemuan pengetahuan data yang dimana tujuan utama dari data mining adalah memanfaatkan data dalam basis data sehingga dapat diolah dan menghasilkan informasi baru yang berguna [6].

Istilah pattern recognition disebut sebagai pengenalan pola yang mempunyai tujuan pengetahuan yang dicari dari dalam basis data yang berisikan banyak data [7]. Jadi, dapat diartikan data mining adalah sebuah proses yang menggunakan beberapa Teknik seperti statistik, matematik, kecerdasan buatan dan machine learning yang bertujuan untuk mengolah dan mengidentifikasi suatu informasi yang berguna dari berbagai himpunan data yang besar [8][9].

\section{B. Clustering}

Clustering merupakan sebuah proses dalam pembentukan kelompok-kelompok data yang berasal dari himpunan data yang belum diketahui kelas-kelasnya dan proses menentukan sebuah data termasuk dalam kelas-kelas tersebut [10][11]. Potensi dari menggunakan clustering adalah dapat digunakan mengetahui struktur-struktur yang berada dalam data dan dapat digunakan dalam berbagai aplikasi seperti, pengenalan pola, pengolahan gambar serta klasifikasi [12][13].

\section{Algoritma K-Means}

Algoritma K-Means merupakan metode non hierarki yang awalnya dapat mengambil sebagian banyak komponen data untuk dapat dijadikan pusat awal cluster. K-Means memiliki kemampuan dalam mengelompokkan data yang jumlahnya besar dengan waktu pemprosesan yang relative cukup cepat dan efisien. Namun, terdapat juga kelemahan dari K-Means yang diakibatkan dalam penentuan pusat awal cluster [14]. Hasil yang terbentuk dari algoritma K-Means ini sangat bergantung pada pemilihan nilai pusat awal cluster. Tahapan dalam melakukan algoritma K-Means dijelaskan sebagai berikut [15]. 1. Menentukan K sebagai jumlah cluster yang akan dibentuk.

2. Menentukan $\mathrm{k}$ titik pusat awal cluster yang dilakukan secara acak. Penentuan pada awal centroid dilakukan secara acak dari data objek yang sudah tersedia sebanyak $\mathrm{k}$ cluster.

3. Menghitung jarak dari setiap data objek ke masing-masing centroid dari beberapa cluster yang ada dengan menggunakan metode perhitungan jarak Euclidean Distance.

4. Alokasikan masing-masing data objek ke dalam cluster dengan cara mengukur jarak kedekatan sifatnya terhadap titik pusat cluster.

5. Melakukan iterasi dan kemudian menentukan posisi centroid baru dengan menggunakan persamaan. Pusat cluster yang baru adalah nilai rata-rata dari semua objek data yang ada dalam cluster tertentu.

6. Ulangi proses perhitungan jika data objek masih berubahubah dan jika pusat cluster tidak berubah maka proses clustering algoritma K-Means dapat dikatakan selesai.

\section{Metode PENELITIAN}

Metode Penelitian yang dilakukan akan menjelaskan tahapan penelitian dan objek penelitian yang akan dijelaskan sebagai berikut.

\section{A. Tahapan Penelitian}

Penelitian Clustering History Data Penjualan Menggunakan Algoritma K-Means dilakukan melalui beberapa tahapan yang terstruktur sehingga proses penelitian dapat dilakukan dengan lebih sistematis, terkontrol dan terarah. Gambar 1 menjelaskan bagaimana proses dilakukannya penerapan algoritma K-Means terhadap history data penjualan.

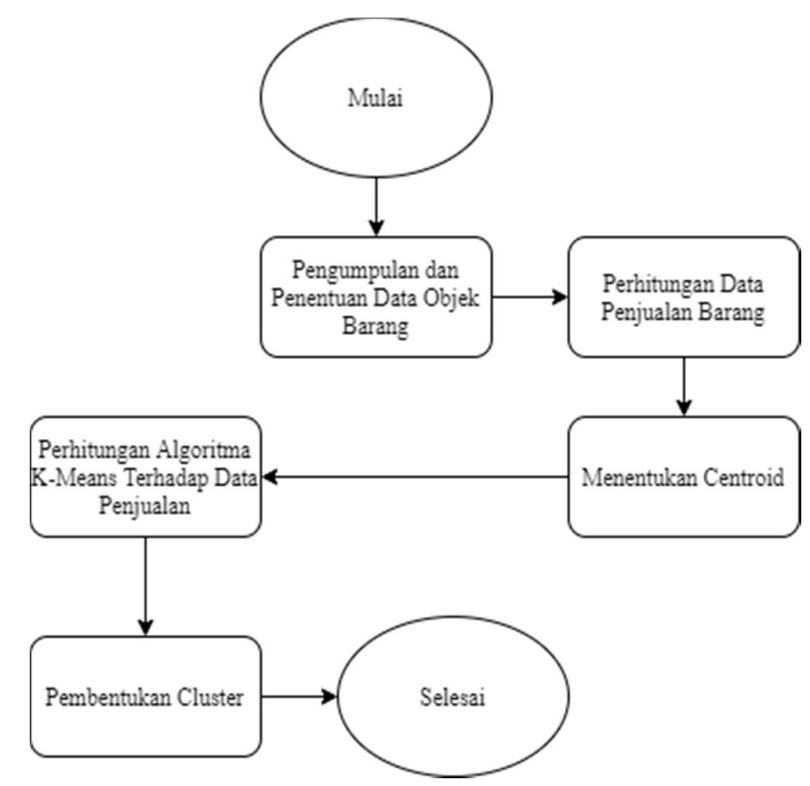

Gambar 1: Alur Proses Penerapan Algoritma K-Means Pada Data Penjualan 
Majalah Ilmiah Teknologi Elektro, Vol. 20, No. 2, Juli-Desember 2021

DOI: https://doi.org/10.24843/MITE.2021.v20i02.P03

Penjelasan dari tahapan penerapan algoritma $K$-Means yang dilkakukan adalah sebagai berikut.

- Pengumpulan dan penentuan data objek barang adalah tahap yang dilakukan untuk mengumpulkan data berupa data barang dari hasil penjulan seperti, laptop, komputer all in one, komputer desktop dan printer yang diambil antara tahun 2019-2020.

- Perhitungan data penjualan barang adalah proses perhitungan dari history penjualan yang telah dilakukan terlihat dari jumlah stok masuk, stok keluar dan sisa stok yang masih tersedia.

- Menentukan banyaknya cluster (k) dari jumlah dataset yang sudah dikumpulkan kemudian menentukan centroid yang biasanya dilakukan secara acak.

- Perhitungan algoritma K-Means terhadap data penjualan adalah melakukan perhitungan dengan menggunakan perhitungan jarak Euclidean Distance terhatap dataset yang sudah tersedia dengan centroid yang sudah ditentukan. Rumus yang digunakan dalam perhitungan jarak sebagai berikut.

$$
d\left(x_{i}, u_{j}\right)=\sqrt{\sum\left(x_{i}, u_{j}\right)^{2}}
$$

- Pembentukan cluster adalah setelah dilakukannya perhitungan maka dataset dikelompokkan berdasarkan kedekatan dengan centroid dan akan terbentuk clustercluster sesuai dengan jumlah cluster (k) yang ditentukan diawal.

\section{B. Objek Penelitian}

Objek penelitian adalah perusahaan $\mathrm{X}$, sebuah perusahaan yang bergerak dalam bidang teknologi informasi dan telekomunikasi yang berlokasi di Provinsi Bali. Data diambil dari data history penjualan dengan dataset sebanyak 23 item barang yang termasuk dalam kategori laptop, komputer all in one, komputer desktop dan printer berdasarkan persediaan yang telah dilakukan dengan berbagai tipe dan jenis. Data berupa data kualitatif yang langsung dapat dihitung sebagai variable bilangan atau angka. Populasi data yang digunakan adalah data history penjualan dan data stok barang dari tahun 2019 sampai 2020.

\section{HASIL DAN PEMBAHASAN}

Hasil dan pembahasan akan menjelaskan tahapan-tahapan dalam penerapan algoritma $K$-Means dari data history penjualan sehingga dapat membentuk sebuah cluster-cluster yang dapat mengkategorikan item barang dari data tersebut.

\section{A. Perhitungan Algoritma K-Means}

Langkah pertama dalam melakukan perhitungan dengan melakukan penentuan nilai centroid awal dan banyaknya cluster. Jumlah cluster ditentukan berdasarkan data penjualan yaitu diminati, cukup diminati dan kurang diminati. Data awal akan diolah ke dalam perhitungan algoritma $K$-Means memiliki 23 jenis barang sesuai kategori masing-masing barang yang

Yogiswara Dharma Putra: Clustering History Data Penjualan... dapat dilihat pada Tabel 1 dan centroid awal (k) yang dapat diambil secara acak pada Tabel 2 sebagai berikut.

TABEL I

DATA PENJUALAN

\begin{tabular}{|c|c|c|c|c|c|}
\hline No & Kategori & Nama Barang & $\begin{array}{c}\text { Stok } \\
\text { Masuk }\end{array}$ & $\begin{array}{c}\text { Stok } \\
\text { Keluar }\end{array}$ & Stok \\
\hline 1 & Laptop & $\begin{array}{l}\text { HP } 240 \mathrm{G} 7 \text { (I7, } \\
4 \mathrm{~GB}, 1 \mathrm{~TB}, \\
\text { AMD 2GB, } \\
\text { WIN10, 14IN) } \\
\text { [6MC33PA] }\end{array}$ & 867 & 794 & 73 \\
\hline 2 & Laptop & $\begin{array}{l}\text { HP 240 G6 (i7, } \\
4 \mathrm{~GB}, 1 \mathrm{~TB}, \\
\text { AMD 2GB, } \\
\text { Win10, 14in) } \\
\text { [4RK12PA] }\end{array}$ & 175 & 174 & 1 \\
\hline 3 & Laptop & $\begin{array}{l}\text { HP } 240 \text { G7 (I5, } \\
4 \mathrm{~GB}, 256 \mathrm{~GB} \\
\mathrm{SSD}, \mathrm{AMD} \\
\text { 2GB, WIN10, } \\
\text { 14IN) } \\
{[6 \mathrm{MW} 37 \mathrm{PA}]}\end{array}$ & 124 & 124 & 0 \\
\hline 4 & Laptop & $\begin{array}{l}\text { HP Probook } 430 \\
\text { G6 (I7, 8GB, } \\
1 \mathrm{~TB}, \mathrm{WIN} 10, \\
13.3 \mathrm{IN}) \\
{[4 \mathrm{SP} 88 \mathrm{AV}]}\end{array}$ & 146 & 140 & 6 \\
\hline 5 & Laptop & $\begin{array}{l}\text { HP EliteBook } \\
830 \text { G5 (I7, } \\
\text { 8GB, 1TB SSD, } \\
\text { WIN10, 13.3IN) } \\
{[2 \text { FZ84AV] }}\end{array}$ & 65 & 32 & 33 \\
\hline 6 & PC AIO & $\begin{array}{l}\text { HP AIO } 200 \mathrm{G} 3 \\
(\mathrm{I} 3,4 \mathrm{~GB}, 1 \mathrm{~TB}, \\
\text { WIN10, 21.5IN, } \\
1 \text { Year) } \\
\text { [4FV35PA] }\end{array}$ & 897 & 806 & 91 \\
\hline 7 & PC AIO & $\begin{array}{l}\text { HP AIO } 200 \mathrm{G} 3 \\
\text { (I5, 4GB, 1TB, } \\
\text { WIN10, 21.5IN, } \\
\text { 1 Year) } \\
\text { [4FV36PA }\end{array}$ & 521 & 464 & 57 \\
\hline 8 & PC AIO & $\begin{array}{l}\text { HP AIO } \\
\text { PROONE 600 } \\
\text { G5 (I5, 8GB, } \\
\text { 1TB } \\
\text { HDD+256GB } \\
\text { SSD, WIN10, } \\
21.5 \mathrm{IN}) \\
\text { [6AE26AV-i5] }\end{array}$ & 891 & 793 & 98 \\
\hline 9 & PC AIO & $\begin{array}{l}\text { HP AIO } \\
\text { PROONE } 400 \\
\text { G4 (I5, 4GB, } \\
\text { 1TB, } \\
\text { WIN10PRO, } \\
\text { 20IN) } \\
{[5 \mathrm{DD} 40 \mathrm{PA}]}\end{array}$ & 180 & 178 & 2 \\
\hline
\end{tabular}




\begin{tabular}{|c|c|c|c|c|c|}
\hline 10 & PC AIO & $\begin{array}{l}\text { HP AIO } \\
\text { PROONE } 400 \\
\text { G4 (I5, 4GB, } \\
\text { 1TB, WIN10 } \\
\text { PRO, 20IN) } \\
\text { [5DD42PA] }\end{array}$ & 475 & 474 & 1 \\
\hline 11 & $\begin{array}{c}\text { PC } \\
\text { Dekstop }\end{array}$ & $\begin{array}{l}\text { HP PC } 280 \text { G4 } \\
\text { MT (I5, 4GB, } \\
\text { 1TB, NVIDIA } \\
2 \mathrm{~GB}, \text { WIN10, } \\
18.5 \mathrm{IN}) \\
{[2 \mathrm{SJ} 42 \mathrm{AV}]}\end{array}$ & 163 & 109 & 54 \\
\hline 12 & $\begin{array}{c}\text { PC } \\
\text { Dekstop }\end{array}$ & $\begin{array}{l}\text { HP PC 280 G4 } \\
\text { MT (I7, 8GB, } \\
\text { 1TB, NVIDIA } \\
\text { 2GB, WIN10, } \\
\text { 20IN) } \\
\text { [2SJ42AV] }\end{array}$ & 911 & 910 & 1 \\
\hline 13 & $\begin{array}{c}\text { PC } \\
\text { Dekstop }\end{array}$ & $\begin{array}{l}\text { HP PC } 260 \text { G3 } \\
\text { DM (I3, 4GB, } \\
1 \mathrm{~TB}, \mathrm{WIN} 10, \\
18.5 \mathrm{IN}) \\
{[3 \mathrm{XT} 51 \mathrm{AV}]}\end{array}$ & 993 & 962 & 31 \\
\hline 14 & $\begin{array}{c}\text { PC } \\
\text { Dekstop }\end{array}$ & $\begin{array}{l}\text { ACER VES2730 } \\
\text { (I5, 8GB, 1TB, } \\
\text { WIN10HOME, } \\
18.5 \mathrm{IN})\end{array}$ & 80 & 35 & 45 \\
\hline 15 & $\begin{array}{c}\text { PC } \\
\text { Dekstop }\end{array}$ & $\begin{array}{l}\text { HP PC } 280 \text { G3 } \\
\text { SFF (I3, 4GB, } \\
1 \mathrm{~TB}, \text { WIN10, } \\
19 \mathrm{IN}) \\
\text { [4LG46PA] }\end{array}$ & 432 & 425 & 7 \\
\hline 16 & Printer & $\begin{array}{l}\text { Epson EcoTank } \\
\text { L3110 All-in- } \\
\text { One Ink Tank } \\
\text { Printer } \\
\end{array}$ & 342 & 342 & 0 \\
\hline 17 & Printer & $\begin{array}{l}\text { EPSON } \\
\text { PRINTER } \\
\text { INKJET } \\
\text { COLOR ECO } \\
\text { TANK L5190 } \\
\text { [C11CG85502] }\end{array}$ & 98 & 98 & 0 \\
\hline 18 & Printer & $\begin{array}{l}\text { EPSON } \\
\text { EcoTank L3150 } \\
\text { Wi-Fi All-in- } \\
\text { One Ink Tank } \\
\text { Printer }\end{array}$ & 125 & 117 & 8 \\
\hline 19 & Printer & $\begin{array}{l}\text { EPSON } \\
\text { ECOTANK } \\
\text { L1110 INK } \\
\text { TANK } \\
\text { PRINTER } \\
\end{array}$ & 126 & 126 & 0 \\
\hline 20 & Printer & $\begin{array}{l}\text { EPSON L120 } \\
\text { Ink Tank Printer }\end{array}$ & 19 & 18 & 1 \\
\hline 21 & Printer & $\begin{array}{l}\text { HP LaserJet Pro } \\
\text { M402n }\end{array}$ & 9 & 4 & 5 \\
\hline 22 & Printer & $\begin{array}{l}\text { HP Laserjet } \\
\text { M203d } \\
{[\mathrm{G} 3 \mathrm{Q} 50 \mathrm{~A}]}\end{array}$ & 21 & 10 & 11 \\
\hline 23 & Printer & $\begin{array}{l}\text { HP Printer Laser } \\
107 w[4 Z B 78 A]\end{array}$ & 39 & 39 & 0 \\
\hline
\end{tabular}

TABEL II

Centroid AWAL

\begin{tabular}{|c|c|c|c|}
\hline Centroid & $\begin{array}{c}\text { Stok } \\
\text { Masuk }\end{array}$ & $\begin{array}{c}\text { Stok } \\
\text { Keluar }\end{array}$ & Stok \\
\hline $\mathrm{C} 1$ & 800 & 580 & 200 \\
\hline $\mathrm{C} 2$ & 500 & 450 & 300 \\
\hline $\mathrm{C} 3$ & 100 & 190 & 95 \\
\hline
\end{tabular}

Selanjutnya dari tiga nilai centroid yang sudah ditentukan secara acak pada Tabel 2 dihitung jaraknya antara data awal dengan centroid menggunakan perhitungan jarak Euclidean Distance dan dikelompokkan berdasarkan kedekatannya sehingga nantinya akan terbentuk tiga cluster sesuai dengan jumlah centroid yang dibentuk. Pada iterasi 1 akan membentuk data seperti pada Tabel 3 sebagai berikut.

\begin{tabular}{|c|c|c|c|c|c|}
\hline \multirow{2}{*}{ No } & \multirow{2}{*}{ Kategori } & \multirow{2}{*}{ Nama Barang } & \multicolumn{3}{|c|}{ Cluster } \\
\hline & & & 1 & 2 & 3 \\
\hline 1 & Laptop & $\begin{array}{l}\text { HP } 240 \text { G7 (I7, } \\
4 \mathrm{~GB}, 1 \mathrm{~TB}, \\
\text { AMD 2GB, } \\
\text { WIN10, 14IN) } \\
\text { [6MC33PA] }\end{array}$ & 257,7 & 551,9 & 976,5 \\
\hline 2 & Laptop & $\begin{array}{l}\text { HP } 240 \text { G6 (i7, } \\
4 \mathrm{~GB}, 1 \mathrm{~TB}, \\
\text { AMD 2GB, } \\
\text { Win10, 14in) } \\
\text { [4RK12PA] }\end{array}$ & 771,4 & 520,8 & 121,3 \\
\hline 3 & Laptop & $\begin{array}{l}\text { HP } 240 \text { G7 (I5, } \\
4 \mathrm{~GB}, 256 \mathrm{~GB} \\
\text { SSD, AMD } \\
\text { 2GB, WIN10, } \\
\text { 14IN) } \\
\text { [6MW37PA] }\end{array}$ & 839,6 & 581,1 & 118,1 \\
\hline 4 & Laptop & $\begin{array}{l}\text { HP Probook } 430 \\
\text { G6 (I7, 8GB, } \\
1 \mathrm{~TB}, \mathrm{WIN} 10, \\
13.3 \mathrm{IN}) \\
{[4 \mathrm{SP} 88 \mathrm{AV}]}\end{array}$ & 811,8 & 554,8 & 112,0 \\
\hline 5 & Laptop & $\begin{array}{l}\text { HP EliteBook } \\
830 \text { G5 (I7, } \\
\text { 8GB, 1TB SSD, } \\
\text { WIN10, 13.3IN) } \\
\text { [2FZ84AV] }\end{array}$ & 931,9 & 659,7 & 173,3 \\
\hline 6 & PC AIO & $\begin{array}{l}\text { HP AIO } 200 \mathrm{G} 3 \\
(\mathrm{I} 3,4 \mathrm{~GB}, 1 \mathrm{~TB}, \\
\text { WIN10, } 21.5 \mathrm{IN}, \\
1 \text { Year) } \\
\text { [4FV35PA] }\end{array}$ & 269,0 & 572,7 & 1007,3 \\
\hline
\end{tabular}




\begin{tabular}{|c|c|c|c|c|c|}
\hline 7 & PC AIO & $\begin{array}{l}\text { HP AIO } 200 \mathrm{G} 3 \\
\text { (I5, 4GB, 1TB, } \\
\text { WIN10, 21.5IN, } \\
\text { 1 Year) } \\
\text { [4FV36PA }\end{array}$ & 334,3 & 244,3 & 503,7 \\
\hline 8 & PC AIO & $\begin{array}{l}\text { HP AIO } \\
\text { PROONE } 600 \\
\text { G5 (I5, 8GB, } \\
1 \mathrm{~TB} \\
\text { HDD+256GB } \\
\text { SSD, WIN10, } \\
\text { 21.5IN) } \\
\text { [6AE26AV-i5] }\end{array}$ & 253,1 & 558,0 & 994,6 \\
\hline 9 & PC AIO & $\begin{array}{l}\text { HP AIO } \\
\text { PROONE } 400 \\
\text { G4 (I5, 4GB, } \\
1 \mathrm{~TB}, \\
\text { WIN10PRO, } \\
\text { 20IN) } \\
\text { [5DD40PA] }\end{array}$ & 765,0 & 515,0 & 123,3 \\
\hline 10 & PC AIO & $\begin{array}{l}\text { HP AIO } \\
\text { PROONE } 400 \\
\text { G4 (I5, 4GB, } \\
\text { 1TB, WIN10 } \\
\text { PRO, 20IN) } \\
\text { [5DD42PA] }\end{array}$ & 395,6 & 301,0 & 479,7 \\
\hline 11 & $\begin{array}{c}\text { PC } \\
\text { Dekstop }\end{array}$ & $\begin{array}{l}\text { HP PC } 280 \mathrm{G} 4 \\
\text { MT (I5, 4GB, } \\
1 \mathrm{~TB}, \text { NVIDIA } \\
2 \mathrm{~GB}, \mathrm{WIN} 10, \\
18.5 \mathrm{IN}) \\
{[2 \mathrm{SJ} 42 \mathrm{AV}]}\end{array}$ & 805,6 & 538,9 & 110,5 \\
\hline 12 & $\begin{array}{c}\text { PC } \\
\text { Dekstop }\end{array}$ & $\begin{array}{l}\text { HP PC } 280 \mathrm{G} 4 \\
\text { MT (I7, 8GB, } \\
\text { 1TB, NVIDIA } \\
2 \mathrm{~GB}, \mathrm{WIN} 10, \\
20 \mathrm{IN}) \\
{[2 \mathrm{SJ} 42 \mathrm{AV}]}\end{array}$ & 401,0 & 685,5 & 1088,6 \\
\hline 13 & $\begin{array}{c}\text { PC } \\
\text { Dekstop }\end{array}$ & $\begin{array}{l}\text { HP PC } 260 \mathrm{G} 3 \\
\text { DM (I3, 4GB, } \\
1 \mathrm{~TB}, \mathrm{WIN} 10, \\
18.5 \mathrm{IN}) \\
{[3 \mathrm{XT} 51 \mathrm{AV}]}\end{array}$ & 460,1 & 760,0 & 1182,2 \\
\hline 14 & $\begin{array}{c}\text { PC } \\
\text { Dekstop }\end{array}$ & $\begin{array}{l}\text { ACER VES2730 } \\
\text { (I5, 8GB, 1TB, } \\
\text { WIN10HOME, } \\
18.5 \mathrm{IN})\end{array}$ & 916,2 & 643,2 & 164,1 \\
\hline 15 & $\begin{array}{c}\text { PC } \\
\text { Dekstop }\end{array}$ & $\begin{array}{l}\text { HP PC } 280 \text { G3 } \\
\text { SFF (I3, 4GB, } \\
1 \mathrm{~TB}, \mathrm{WIN} 10 \text {, } \\
19 \mathrm{IN}) \\
{[4 \mathrm{LG} 46 \mathrm{PA}]}\end{array}$ & 443,5 & 301,8 & 416,2 \\
\hline 16 & Printer & $\begin{array}{l}\text { Epson EcoTank } \\
\text { L3110 All-in- } \\
\text { One Ink Tank } \\
\text { Printer }\end{array}$ & 553,5 & 355,8 & 301,2 \\
\hline 17 & Printer & $\begin{array}{l}\text { EPSON } \\
\text { PRINTER } \\
\text { INKJET } \\
\text { COLOR ECO } \\
\text { TANK L5190 } \\
{[\text { C11CG85502] }}\end{array}$ & 874,7 & 612,8 & 132,3 \\
\hline
\end{tabular}

\begin{tabular}{|c|c|l|c|c|c|}
\hline 18 & Printer & $\begin{array}{l}\text { EPSON } \\
\text { EcoTank L3150 } \\
\text { Wi-Fi All-in- } \\
\text { One Ink Tank } \\
\text { Printer }\end{array}$ & 840,7 & 580,3 & 116,3 \\
\hline 19 & Printer & $\begin{array}{l}\text { EPSON } \\
\text { ECOTANK } \\
\text { L1110 INK } \\
\text { TANK } \\
\text { PRINTER }\end{array}$ & 836,9 & 578,7 & 117,5 \\
\hline 20 & Printer & $\begin{array}{l}\text { EPSON L120 } \\
\text { Ink Tank Printer }\end{array}$ & 982,6 & 712,3 & 212,1 \\
\hline 21 & Printer & $\begin{array}{l}\text { HP LaserJet Pro } \\
\text { M402n }\end{array}$ & 997,7 & 726,0 & 225,8 \\
\hline 22 & Printer & $\begin{array}{l}\text { HP Laserjet } \\
\text { M203d } \\
\text { [G3Q50A] }\end{array}$ & 983,6 & 711,7 & 213,8 \\
\hline Printer & $\begin{array}{l}\text { HP Printer Laser } \\
\text { 107w [4ZB78A] }\end{array}$ & 954,9 & 686,6 & 188,5 \\
\hline
\end{tabular}

Dari perhitungan iterasi 1 dihitung rata-rata nilai centroidnya sehingga mendapatkan nilai centroid baru yang akan digunakan dalam perhitungan iterasi selanjutnya. Nilai rata-rata pada iterasi 1 dapat dilihat pada Tabel 4 sebagai berikut.

TABEL IV

CENTROID BARU

\begin{tabular}{|c|c|c|c|c|}
\hline \multirow{4}{*}{$\begin{array}{c}\text { Nilai } \\
\text { Rata- }\end{array}$} & Centroid & $\begin{array}{c}\text { Stok } \\
\text { Masuk }\end{array}$ & $\begin{array}{c}\text { Stok } \\
\text { Keluar }\end{array}$ & Stok \\
\cline { 2 - 5 } Rata & $\mathrm{C} 1$ & 915,5 & 864,75 & 50,75 \\
\cline { 2 - 5 } & $\mathrm{C} 2$ & 581,25 & 542,25 & 39 \\
\cline { 2 - 5 } & $\mathrm{C} 3$ & 114,133 & 103,066 & 11,066 \\
\hline
\end{tabular}

Kemudian ulangi proses perhitungan algoritma $\mathrm{K}$-Means seperti pada iterasi 1 sehingga mendapatkan anggota cluster yang tidak berubah maka iterasi dapat dikatakan berhenti atau sampai pada tahap terakhir. Pada penelitian ini iterasi berhenti pada iterasi 4 yang tidak terjadi perubahan pada anggota cluster yang ditunjukkan pada Tabel 5 sebagai berikut.

TABEL V

ITERASI 4

\begin{tabular}{|c|c|c|c|c|c|}
\hline \multirow{2}{*}{ No } & \multirow{2}{*}{ Kategori } & \multirow{2}{*}{ Nama Barang } & \multicolumn{3}{|c|}{ Cluster } \\
\hline & & & 1 & 2 & 3 \\
\hline 1 & Laptop & $\begin{array}{l}\text { HP } 240 \text { G7 (I7, } \\
4 \mathrm{~GB}, 1 \mathrm{~TB}, \\
\text { AMD 2GB, } \\
\text { WIN10, 14IN) } \\
{[6 \mathrm{MC} 33 \mathrm{PA}]}\end{array}$ & 75,4 & 564,5 & 1047,2 \\
\hline 2 & Laptop & $\begin{array}{l}\text { HP } 240 \text { G6 (i7, } \\
\text { 4GB, 1TB, } \\
\text { AMD 2GB, } \\
\text { Win10, 14in) } \\
\text { [4RK12PA] }\end{array}$ & 1003,6 & 368,0 & 117,5 \\
\hline
\end{tabular}

p-ISSN:1693 - 2951; e-ISSN: 2503-2372

Yogiswara Dharma Putra: Clustering History Data Penjualan... 


\begin{tabular}{|c|c|c|c|c|c|}
\hline 3 & Laptop & $\begin{array}{l}\text { HP 240 G7 (I5, } \\
4 \mathrm{~GB}, 256 \mathrm{~GB} \\
\mathrm{SSD}, \text { AMD } \\
\text { 2GB, WIN10, } \\
14 \mathrm{IN}) \\
\text { [6MW37PA] }\end{array}$ & 1075,0 & 439,4 & 47,6 \\
\hline 4 & Laptop & $\begin{array}{l}\text { HP Probook } \\
430 \text { G6 (I7, } \\
8 \mathrm{~GB}, 1 \mathrm{~TB}, \\
\text { WIN10, } \\
13.3 \mathrm{IN}) \\
{[4 \mathrm{SP} 88 \mathrm{AV}]}\end{array}$ & 1047,7 & 412,3 & 72,6 \\
\hline 5 & Laptop & $\begin{array}{l}\text { HP EliteBook } \\
830 \text { G5 (I7, } \\
\text { 8GB, 1TB } \\
\text { SSD, WIN10, } \\
\text { 13.3IN) } \\
{[2 \text { FZ84AV] }}\end{array}$ & 1179,7 & 546,1 & 66,7 \\
\hline 6 & PC AIO & $\begin{array}{l}\text { HP AIO } 200 \\
\text { G3 (I3, 4GB, } \\
\text { 1TB, WIN10, } \\
\text { 21.5IN, 1 Year) } \\
\text { [4FV35PA] }\end{array}$ & 58,9 & 597,0 & 1078,6 \\
\hline 7 & PC AIO & $\begin{array}{l}\text { HP AIO } 200 \\
\text { G3 (I5, 4GB, } \\
\text { 1TB, WIN10, } \\
\text { 21.5IN, 1 Year) } \\
\text { [4FV36PA }\end{array}$ & 551,4 & 96,2 & 569,2 \\
\hline 8 & PC AIO & $\begin{array}{l}\text { HP AIO } \\
\text { PROONE 600 } \\
\text { G5 (I5, 8GB, } \\
\text { 1TB } \\
\text { HDD+256GB } \\
\text { SSD, WIN10, } \\
\text { 21.5IN) } \\
\text { [6AE26AV-i5] }\end{array}$ & 74,6 & 585,1 & 1066,0 \\
\hline 9 & PC AIO & $\begin{array}{l}\text { HP AIO } \\
\text { PROONE } 400 \\
\text { G4 (I5, 4GB, } \\
1 \mathrm{~TB}, \\
\text { WIN10PRO, } \\
\text { 20IN) } \\
\text { [5DD40PA] }\end{array}$ & 997,2 & 361,6 & 123,7 \\
\hline 10 & PC AIO & $\begin{array}{l}\text { HP AIO } \\
\text { PROONE } 400 \\
\text { G4 (I5, 4GB, } \\
\text { 1TB, WIN10 } \\
\text { PRO, 20IN) } \\
\text { [5DD42PA] }\end{array}$ & 581,2 & 59,7 & 541,2 \\
\hline 11 & $\begin{array}{c}\text { PC } \\
\text { Dekstop }\end{array}$ & $\begin{array}{l}\text { HP PC } 280 \mathrm{G} 4 \\
\text { MT (I5, 4GB, } \\
1 \mathrm{~TB}, \text { NVIDIA } \\
2 \mathrm{~GB}, \mathrm{WIN} 10, \\
18.5 \mathrm{IN}) \\
{[2 \mathrm{SJ} 42 \mathrm{AV}]}\end{array}$ & 1055,6 & 424,5 & 80,9 \\
\hline 12 & $\begin{array}{c}\text { PC } \\
\text { Dekstop }\end{array}$ & $\begin{array}{l}\text { HP PC } 280 \text { G4 } \\
\text { MT (I7, 8GB, } \\
1 \mathrm{~TB}, \text { NVIDIA } \\
2 \mathrm{~GB}, \text { WIN10, } \\
20 \mathrm{IN}) \\
{[2 \mathrm{SJ} 42 \mathrm{AV}]}\end{array}$ & 81,2 & 673,6 & 1157,7 \\
\hline
\end{tabular}

\begin{tabular}{|c|c|c|c|c|c|}
\hline 13 & $\begin{array}{c}\text { PC } \\
\text { Dekstop }\end{array}$ & $\begin{array}{l}\text { HP PC } 260 \text { G3 } \\
\text { DM (I3, 4GB, } \\
1 \mathrm{~TB}, \mathrm{WIN} 10, \\
18.5 \mathrm{IN}) \\
{[3 \mathrm{XT} 51 \mathrm{AV}]}\end{array}$ & 138,7 & 768,3 & 1252,6 \\
\hline 14 & $\begin{array}{c}\text { PC } \\
\text { Dekstop }\end{array}$ & $\begin{array}{l}\text { ACER } \\
\text { VES2730 (I5, } \\
8 \mathrm{~GB}, 1 \mathrm{~TB}, \\
\text { WIN10HOME, } \\
18.5 \mathrm{IN})\end{array}$ & 1166,7 & 534,1 & 63,4 \\
\hline 15 & $\begin{array}{c}\text { PC } \\
\text { Dekstop }\end{array}$ & $\begin{array}{l}\text { HP PC } 280 \text { G3 } \\
\text { SFF (I3, 4GB, } \\
1 \mathrm{~TB}, \mathrm{WIN} 10, \\
19 \mathrm{IN}) \\
{[4 \mathrm{LG} 46 \mathrm{PA}]}\end{array}$ & 645,0 & 14,0 & 476,0 \\
\hline 16 & Printer & $\begin{array}{l}\text { Epson EcoTank } \\
\text { L3110 All-in- } \\
\text { One Ink Tank } \\
\text { Printer }\end{array}$ & 767,6 & 132,1 & 354,0 \\
\hline 17 & Printer & $\begin{array}{l}\text { EPSON } \\
\text { PRINTER } \\
\text { INKJET } \\
\text { COLOR ECO } \\
\text { TANK L5190 } \\
\text { [C11CG85502] }\end{array}$ & 1111,6 & 476,1 & 16,9 \\
\hline 18 & Printer & $\begin{array}{l}\text { EPSON } \\
\text { EcoTank } \\
\text { L3150 Wi-Fi } \\
\text { All-in-One Ink } \\
\text { Tank Printer }\end{array}$ & 1078,6 & 443,3 & 41,4 \\
\hline 19 & Printer & $\begin{array}{l}\text { EPSON } \\
\text { ECOTANK } \\
\text { L1110 INK } \\
\text { TANK } \\
\text { PRINTER } \\
\end{array}$ & 1072,1 & 436,6 & 50,3 \\
\hline 20 & Printer & $\begin{array}{l}\text { EPSON L120 } \\
\text { Ink Tank } \\
\text { Printer }\end{array}$ & 1223,8 & 588,4 & 104,7 \\
\hline 21 & Printer & $\begin{array}{l}\text { HP LaserJet } \\
\text { Pro M402n }\end{array}$ & 1240,5 & 605,3 & 121,1 \\
\hline 22 & Printer & $\begin{array}{l}\text { HP Laserjet } \\
\text { M203d } \\
{[\mathrm{G} 3 \mathrm{Q} 50 \mathrm{~A}]}\end{array}$ & 1227,4 & 592,4 & 108,1 \\
\hline 23 & Printer & $\begin{array}{l}\text { HP Printer } \\
\text { Laser 107w } \\
\text { [4ZB78A] }\end{array}$ & 1194,9 & 559,5 & 76,2 \\
\hline
\end{tabular}

Pada iterasi 4 dihitung nilai rata-rata centroid-nya dan mendapatkan hasil nilai centroid yang tidak berubah seperti pada Tabel 6 sebagai berikut.

\begin{tabular}{|c|c|c|c|c|}
\hline \multicolumn{5}{|c|}{$\begin{array}{c}\text { TABEL VI } \\
\text { CENTROID TERAKHIR }\end{array}$} \\
\hline \multirow{4}{*}{$\begin{array}{l}\text { Nilai } \\
\text { Rata- } \\
\text { Rata }\end{array}$} & Centroid & $\begin{array}{c}\text { Stok } \\
\text { Masuk }\end{array}$ & $\begin{array}{c}\text { Stok } \\
\text { Keluar }\end{array}$ & Stok \\
\hline & $\mathrm{C} 1$ & 911,8 & 853 & 58,8 \\
\hline & $\mathrm{C} 2$ & 442,5 & 426,25 & 16,25 \\
\hline & $\mathrm{C} 3$ & 97,857 & 86 & 11,85714 \\
\hline
\end{tabular}


Majalah Ilmiah Teknologi Elektro, Vol. 20, No. 2, Juli - Desember 2021

DOI: https://doi.org/10.24843/MITE.2021.v20i02.P03

Grafik terkahir yang dapat dilihat setelah melakukan perhitungan algoritma K-Means menunjukkan hasil dari pembentukan cluster dari setiap item barang seperti pada Gambar 2 sebagai berikut.

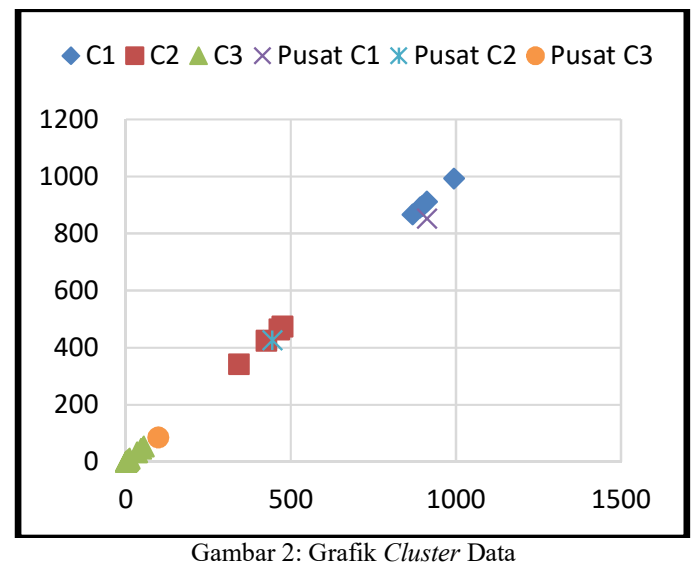

Berdasarkan hasil dari perhitungan algoritma $K$-Means maka ketiga cluster tersebut mewakili tingkat penjualan dari item barang yang memiliki kategori sangat diminati, diminati dan kurang diminati yang dapat ditunjukkan pada tabel 7,8,9 sebagai berikut.

TABEL VII

CLUSTER 1

\begin{tabular}{|c|c|l|}
\hline \multicolumn{2}{|c|}{ Cluster 1 } \\
\hline \multirow{1}{*}{$\begin{array}{c}\text { Langat } \\
\text { Diminati }\end{array}$} & PC AIO & $\begin{array}{l}\text { HP 240 G7 (I7, 4GB, 1TB, AMD } \\
\text { 2GB, WIN10, 14IN) [6MC33PA] }\end{array}$ \\
\cline { 2 - 3 } & PC AIO & $\begin{array}{l}\text { HP AIO 200 G3 (I3, 4GB, 1TB, } \\
\text { WIN10, 21.5IN, 1 Year) } \\
\text { [4FV35PA] }\end{array}$ \\
\cline { 2 - 3 } & $\begin{array}{l}\text { HP AIO PROONE 600 G5 (I5, } \\
\text { WIN10, 21.5IN) [6AE26AV-i5] }\end{array}$ \\
\cline { 2 - 3 } & PC Dekstop & $\begin{array}{l}\text { HP PC 280 G4 MT (I7, 8GB, } \\
\text { 1TB, NVIDIA 2GB, WIN10, } \\
\text { 20IN) [2SJ42AV] }\end{array}$ \\
\cline { 2 - 3 } & PC Dekstop & $\begin{array}{l}\text { HP PC 260 G3 DM (I3, 4GB, } \\
\text { 1TB, WIN10, 18.5IN) } \\
\text { [3XT51AV] }\end{array}$ \\
\hline
\end{tabular}

\begin{tabular}{|c|c|c|}
\hline \multicolumn{3}{|r|}{$\begin{array}{l}\text { TABEL VIII } \\
\text { CLUSTER } 2\end{array}$} \\
\hline \multicolumn{3}{|r|}{ Cluster 2} \\
\hline \multirow{3}{*}{ Diminati } & PC AIO & $\begin{array}{l}\text { HP AIO } 200 \text { G3 (I5, 4GB, 1TB, } \\
\text { WIN10, 21.5IN, } 1 \text { Year) [4FV36PA }\end{array}$ \\
\hline & PC AIO & $\begin{array}{l}\text { HP AIO PROONE } 400 \text { G4 (I5, } \\
\text { 4GB, 1TB, WIN10 PRO, 20IN) } \\
{[5 \mathrm{DD} 42 \mathrm{PA}]}\end{array}$ \\
\hline & $\begin{array}{c}\text { PC } \\
\text { Dekstop }\end{array}$ & $\begin{array}{l}\text { HP PC } 280 \mathrm{G} 3 \mathrm{SFF}(\mathrm{I} 3,4 \mathrm{~GB}, 1 \mathrm{~TB}, \\
\text { WIN10, 19IN) [4LG46PA] }\end{array}$ \\
\hline
\end{tabular}

Yogiswara Dharma Putra: Clustering History Data Penjualan...

\begin{tabular}{|c|c|c|c|}
\hline & \multicolumn{2}{|c|}{ Printer } & $\begin{array}{l}\text { Epson EcoTank L3110 All-in-One } \\
\text { Ink Tank Printer }\end{array}$ \\
\hline \multicolumn{4}{|r|}{$\begin{array}{l}\text { TABEL IX } \\
\text { CLUSTER } 3\end{array}$} \\
\hline \multicolumn{4}{|r|}{ Cluster 3} \\
\hline \multirow{14}{*}{$\begin{array}{l}\text { Kurang } \\
\text { Diminati }\end{array}$} & Laptop & & $\begin{array}{l}240 \text { G6 (i7, 4GB, 1TB, AMD 2GB, } \\
\text { 10, 14in) [4RK12PA] }\end{array}$ \\
\hline & Laptop & & $\begin{array}{l}240 \mathrm{G} 7(\mathrm{I} 5,4 \mathrm{~GB}, 256 \mathrm{~GB} \mathrm{SSD}, \mathrm{AMD} \\
\text {, WIN10, 14IN) [6MW37PA] }\end{array}$ \\
\hline & Laptop & & $\begin{array}{l}\text { Probook } 430 \mathrm{G} 6(\mathrm{I} 7,8 \mathrm{~GB}, 1 \mathrm{~TB}, \\
\mathrm{J} 10,13.3 \mathrm{IN})[4 \mathrm{SP} 88 \mathrm{AV}]\end{array}$ \\
\hline & Laptop & & $\begin{array}{l}\text { EliteBook } 830 \text { G5 (I7, 8GB, 1TB } \\
\text {, WIN10, 13.3IN) [2FZ84AV] }\end{array}$ \\
\hline & $\mathrm{PC}$ AIO & & $\begin{array}{l}\text { AIO PROONE } 400 \mathrm{G} 4 \text { (I5, 4GB, } \\
\text {, WIN10PRO, 20IN) [5DD40PA] }\end{array}$ \\
\hline & $\begin{array}{l}\text { PC } \\
\text { Dekstop }\end{array}$ & & $\begin{array}{l}\text { PC } 280 \mathrm{G} 4 \mathrm{MT}(\mathrm{I} 5,4 \mathrm{~GB}, 1 \mathrm{~TB}, \\
\text { DIA } 2 \mathrm{~GB}, \mathrm{WIN} 10,18.5 \mathrm{IN}) \\
42 \mathrm{AV}]\end{array}$ \\
\hline & $\begin{array}{c}\text { PC } \\
\text { Dekstop }\end{array}$ & & $\begin{array}{l}\text { R VES2730 (I5, 8GB, 1TB, } \\
\text { I10HOME, 18.5IN) }\end{array}$ \\
\hline & Printer & $\begin{array}{l}\mathrm{EP} \\
\mathrm{EC}\end{array}$ & $\begin{array}{l}\text { ON PRINTER INKJET COLOR } \\
\text { TANK L5190 [C11CG85502] }\end{array}$ \\
\hline & Printer & $\begin{array}{l}\text { EP } \\
\text { On }\end{array}$ & $\begin{array}{l}\text { ON EcoTank L3150 Wi-Fi All-in- } \\
\text { Ink Tank Printer }\end{array}$ \\
\hline & Printer & $\begin{array}{l}\mathrm{EP} \\
\mathrm{PR}\end{array}$ & $\begin{array}{l}\text { ON ECOTANK L1110 INK TANK } \\
\text { NTER }\end{array}$ \\
\hline & Printer & EP & ON L120 Ink Tank Printer \\
\hline & Printer & HP & LaserJet Pro M402n \\
\hline & Printer & HP & Laserjet M203d [G3Q50A] \\
\hline & Printer & HP & Printer Laser 107w [4ZB78A] \\
\hline
\end{tabular}

Cluster 1,2,3 menunjukkan hasil dari pembentukan cluster dari penerapan algoritma K-Means. Hasil tersebut memperlihatkan item barang yang memiliki tingkat penjualan berdasarkan dari data awal yang telah diolah. Pada cluster 1 memiliki 5 jumlah item barang, cluster 2 memiliki 4 jumlah item barang dan cluster 3 memiliki 14 item barang yang memperhitungkan history penjualan dari tahun 2019 sampai 2020. Stok masuk, stok keluar dan sisa stok yang tersedia menjadi faktor utama dalam penentuan dari item barang yang memiliki tingkat penjualan yang paling diminati, karena perhitungan dilakukan menggunakan data dua tahun penjualan

p-ISSN:1693 - 2951; e-ISSN: 2503-2372 
sehingga memperlihatkan dari jumlah barang yang masuk dan keluar.

\section{KESIMPULAN}

Berdasarkan hasil yang didapatkan menggunakan algoritma $K$-Means pada 23 item data penjualan dari persediaan barang yang telah dilakukan dari tahun 2019 sampai 2020 dengan kategori barang laptop, komputer dan printer yang menghasilkan 3 cluster yang di interpretasikan sangat diminati, diminati dan kurang diminati. Dari 3 cluster yang terbentuk dengan titik centoid awal yaitu C1 $(800,580,200), C 2(500,450$, 300) dan C3 $(100,190,95)$ maka proses akhir berhenti pada iterasi ke 4 yang mendapatkan data pada cluster 1 atau sangat diminati memiliki 5 barang, cluster 2 atau diminati memiliki 4 barang dan cluster 3 atau kurang diminati memiliki 14 barang yang memiliki titik centroid akhir yaitu $\mathrm{C} 1(911.8,853,58.8)$, C2 $(442.5,426.25,16.25)$ dan C3 $(97.85,86,11.85)$.

\section{REFERENSI}

[1] S. Samudi, S. Widodo, and H. Brawijaya, "The K-Medoids Clustering Method for Learning Applications during the COVID-19 Pandemic," SinkrOn, vol. 5, no. 1, p. 116, 2020, doi: 10.33395/sinkron.v5i1.10649.

[2] A. Primandana, S. Adinugroho, and C. Dewi, "Optimasi Penentuan Centroid pada Algoritme K-Means Menggunakan Algoritme Pillar (Studi Kasus: Penyandang Masalah Kesejahteraan Sosial di Provinsi ...," ... Teknol. Inf. dan Ilmu ..., vol. 3, no. 11, pp. 10678-10683, 2020, [Online]. Available: ptiik/article/download/6748/3264.

[3] A. W. Oktavia Gama, I. K. Gede Darma Putra, and I. P. Agung Bayupati, "Implementasi Algoritma Apriori Untuk Menemukan Frequent Itemset Dalam Keranjang Belanja," Maj. Ilm. Teknol. Elektro, vol. 15, no. 2, pp. 21-26, 2016, doi: 10.24843/mite.1502.04.

[4] S. S. Nagari and L. Inayati, "Implementation of Clustering Using K-Means Method To Determine Nutritional Status," $J$. Biometrika dan Kependud., vol. 9, no. 1, p. 62, 2020, doi: 10.20473/jbk.v9i1.2020.62-68.

[5] S. Saefudin and D. Fernando, "Penerapan Data Mining Rekomendasi Buku Menggunakan Algoritma Apriori," JSiI (Jurnal Sist. Informasi), vol. 7, no. 1, p. 50, 2020, doi: 10.30656/jsii.v7i1.1899.

[6] I. Parlina, W. Agus Perdana, W. Anjar, and L. M.Ridwan, "Memanfaatkan Algoritma K-Means Dalam Menentukan Pegawai Yang Layak Mengikuti Asessment Center," Memanfaatkan Algoritm. K-Means Dalam Menentukan Pegawai Yang Layak Mengikuti Asessment Cent. Untuk Clust. Progr. Sdp, vol. 3, no. 1, pp. 87-93, 2018.

[7] M. S. Mustafa, M. R. Ramadhan, and A. P. Thenata, "Implementasi Data Mining untuk Evaluasi Kinerja Akademik Mahasiswa Menggunakan Algoritma Naive Bayes Classifier," Creat. Inf. Technol. J., vol. 4, no. 2, p. 151, 2018, doi: 10.24076/citec.2017v4i2.106.

[8] H. Priyatman, F. Sajid, and D. Haldivany, "Klasterisasi Menggunakan Algoritma K-Means Clustering untuk Memprediksi Waktu Kelulusan Mahasiswa," J. Edukasi dan Penelit. Inform., vol. 5, no. 1, p. 62, 2019, doi: 10.26418/jp.v5i1.29611.

[9] I. S. Melati, L. Linawati, and I. A. . Giriantari, "Knowledge Discovery Data Akademik Untuk Prediksi Pengunduran Diri Calon Mahasiswa," Maj. Ilm. Teknol. Elektro, vol. 17, no. 3, p. 325, 2018, doi: 10.24843/mite.2018.v17i03.p04

[10] E. Ainun, W. Isti, and S. Fachri, "Implementasi Algoritma K - Means Clustering Tingkat Kepentingan Tagihan Rumah Sakit Di Pt Pertamina ( Persero ), 2020.

[11] A. A. G. B. Ariana, I. K. G. Darma Putra, and L. Linawati, "Perbandingan Metode SOM/Kohonen dengan ART 2 pada Data Mining Perusahaan Retail," Maj. Ilm. Teknol. Elektro, vol. 16, no. 2, p. 55, 2017, doi: 10.24843/mite.2017.v16i02p10.

[12] M. Pasek, A. Ariawan, N. P. Sastra, and I. M. Sudarma, "KMean s Clustering Dan Local Outlier Factor," vol. 19, no. 1, 2020.

[13] N. G. Yudiarta, M. Sudarma, and W. G. Ariastina, "Penerapan Metode Clustering Text Mining Untuk Pengelompokan Berita Pada Unstructured Textual Data," Maj. Ilm. Teknol. Elektro, vol. 17, no. 3, p. 339, 2018, doi: 10.24843/mite.2018.v17i03.p06.

[14] S. Butsianto and N. T. Mayangwulan, "Penerapan Data Mining Untuk Prediksi Penjualan Mobil Menggunakan Metode K-Means Clustering," J. Nas. Komputasi dan Teknol. Inf., vol. 3, no. 3, pp. 187-201, 2020, doi: 10.32672/jnkti.v3i3.2428.

[15] G. Gustientiedina, M. H. Adiya, and Y. Desnelita, "Penerapan Algoritma K-Means Untuk Clustering Data Obat-Obatan," J. Nas. Teknol. dan Sist. Inf., vol. 5, no. 1, pp. 17-24, 2019, doi: 10.25077/teknosi.v5i1.2019.17-24.

[16] Y. K. Siregar, "Analisis perbandingan algoritma," vol. 2, no. 1, pp. 151-155, 2019.

[17] A. A. Rismayadi, N. N. Fatonah, dan Erfin Junianto, "Algoritma K-Means Clustering Untuk Menentukan Strategi Pemasaran Di CV. Integreet Konstruksi," Jurnal Responsif, vol. 3, no. 1, pp. 30-36, 2021, [Online]. Available: http://ejurnal.ars.ac.id/index.php/jti/article/view/393.

[18] O. N. Pratiwi, "Analisa Perbandingan Algoritma K-Means, Decision Tree, Dan Naïve Bayes Untuk Sistem Pengelompokkan Siswa Otomatis,"Jurnal Ilmiah Teknologi Informasi Terapan., vol. II, no. 2, pp. 109-118, 2016.

[19] R. A. M. S. D. Yuhandri, "Perbandingan Algoritma K-Means Clustering Dengan Fuzzy C- Means Dalam Mengukur Tingkat Kepuasan Terhadap Televisi Dakwah Suaru TV," Jurnal Teknologi dan Sistem Informasi Univrab, vol. 3, no. 1, pp. 10-21, 2018.

[20] M. Y. Rizki, S. Maysaroh, and A. P. Windarto, "Implementasi K-Means Clushtering Dalam Mengelompokkan Minat Membaca Penduduk Menurut Wilayah," JUST IT Jurnal Sistem Informasi, Teknologi Informasi dan Komputer, vol. 11, no. 2, pp. 41-49, 2021, [Online]. Available: https://jurnal.umj.ac.id/index.php/justit/article/view/5902.

[21] N. A. S. Damanik, Irianto, dan Dahriansah "Penerapan Metode Clustering Dengan Algoritma K-Means Tindakan Kejahatan Pencurian di Kabupaten Asahan.,"J-Com (Journal of Computer) vol. 1, no. 1, pp. 7-14, 2021, [Online]. Available: http:// jurnal.stmikroyal.ac.id/index.php/j-com 